\title{
Longitudinal evaluation of Ocimum and other plants effects on the feeding behavioral response of mosquitoes (Diptera: Culicidae) in the field in Tanzania
}

\author{
Eliningaya J Kweka*1,2, Franklin W Mosha², Asanterabi Lowassa ${ }^{3}$, \\ Aneth M Mahande ${ }^{1,2}$, Michael J Mahande ${ }^{1}$, Charles P Massenga1, \\ Filemoni Tenu ${ }^{4}$, Ester E Lyatuu ${ }^{1}$, Michael A Mboya ${ }^{1}$ and Emmanuel A Temu ${ }^{5}$
}

\begin{abstract}
Address: ${ }^{1}$ Tropical Pesticides Research Institute, Division of Livestock and Human Disease Vector Control, P.O. Box 3024, Arusha-Tanzania, ${ }^{2}$ KCM College of Tumaini University P.O. Box 2240, Moshi, Tanzania, ${ }^{3}$ Tanzania Wildlife Research Institute, P.O. Box 661, Arusha, Tanzania, ${ }^{4}$ National Institute for Medical Research, Ubwari Field station, P.O.Box 81, Muheza, Tanzania and ${ }^{5}$ Institute of Tropical Medicine, Nagasaki University, 112-4 Sakamoto, Nagasaki, Japan

Email: Eliningaya J Kweka* - pat.kweka@gmail.com; Franklin W Mosha - fwmosha@ hotmail.com; Asanterabi Lowassa - alowassa@yahoo.co.uk; Aneth M Mahande - anethf@yahoo.co.uk; Michael J Mahande - pat.kweka@gmail.com; Charles P Massenga - pat.kweka@gmail.com; Filemoni Tenu - Filemonitenu@yahoo.co.uk; Ester E Lyatuu - eeliasl@yahoo.com;

Michael A Mboya - pat.kweka@gmail.com; Emmanuel A Temu - emmanuel.temu@gmail.com

* Corresponding author
\end{abstract}

Published: 22 October 2008

Parasites \& Vectors 2008, I:42 doi:10.1 I86/1756-3305-I-42
Received: 10 July 2008

Accepted: 22 October 2008

This article is available from: http://www.parasitesandvectors.com/content/l/l/42

(c) 2008 Kweka et al; licensee BioMed Central Ltd.

This is an Open Access article distributed under the terms of the Creative Commons Attribution License (http://creativecommons.org/licenses/by/2.0), which permits unrestricted use, distribution, and reproduction in any medium, provided the original work is properly cited.

\begin{abstract}
Background: The use of repellent materials from plants against nuisance insects is common with great potential to compliment existing malaria control programmes and this requires evaluation in the field. Ocimum plant species, Ocimum suave (Willd) and $O$. kilimandscharicum (Guerke) materials and their essential oils extracted by steam distillation were evaluated in the field and experimental huts for repellence, exophily and feeding inhibition effects against three mosquito species, Anopheles arabiensis (Patton), An. gambiae ss (Giles) and Culex quinquefasciatus (Say). The protective effect of essential oils from Ocimum plants were compared with N, Ndiethly-3- methylbenzamide (DEET), a standard synthetic repellent. Also, the protective effect of fumigation by burning of repellent plants; Ocimum suave, Ocimum kilimandscharicum, Azadirachta indica, Eucalyptus globules and Lantana camara were tested in experimental huts and selected local houses.
\end{abstract}

Results: In the field, protection by Ocimum plants from mosquito bites was high and there was small variation among different mosquito species. Protection efficiency was $93.4 \%, 91.98 \%$ and $89.75 \%$ for An. arabiensis while for Cx. quinquefaciatus it was $91.30 \%, 88.65 \%$ and $90.50 \%$ for DEET, Ocimum suave and 0 . kilimandscharicum respectively. In the experimental hut, deterrence induced by burning of Ocimum and other plants ranged from 73.1.0\% to $81.9 \%$ for An. arabiensis and $56.5 \%$ to $67.8 \%$ for $C_{x}$. quinquefaciatus, while feeding inhibition was $61.1 \%$ to $100 \%$ for An. arabiensis and $50 \%$ to $100 \%$ for $C x$. quinquefaciatus. Evaluations under field conditions confirmed high protective efficacy, enhanced feeding inhibition and house entry inhibition (Deterrence).

Conclusion: This study shows the potential of Ocimum suave and Ocimum kilimandscharicum crude extracts and whole plants of Ocimum suave, Ocimum kilimandscharicum, Azadirachta indica, Eucalyptus globules and Lantana camara for use in protecting against human biting while the burning of plants reduces significantly the indoor resting mosquitoes. 


\section{Background}

Since ancient times, several plants and plant products have been used locally to repel or kill mosquitoes. There are several plants in sub-Saharan Africa reported to constitute effective repellents effect against arthropods of vectorborne disease [1-5]. Some of these plants, for example citronella and pyrethrum, have been commercialised and are effectively used as mosquito repellents [3].

In lower Moshi villages, we investigated whether whole plant and plant products derived from local areas can be used in combination with the bed nets to provide protection against malaria vectors and nuisance biting insects. Before starting such an investigation, we conducted an ethnobotanical survey to understand the common knowledge, attitude and practices, of local people, on the use of plant products for protection against mosquitoes and other biting insects. At Lower Moshi, Ocimum suave, Ocimum kilimandscharicum, Azadirachta indica, Eucalyptus globules and Lantana camara plants are common and known to have provide protection against mosquitoes [6]. These aromatic plants, Ocimum suave (OS) and Ocimum kilimandscharicum (OK) locally know as a broom "Ufagio", in the Kiswahili language, belong to the family Lamiaceae and are the focus of this study. Several plants of this family have been proven to have insecticidal and repellent effects, used widely against blood- feeding arthropods and those feeding on crops [7-11].

Although, treated mosquito nets have been proved to be effective in reducing child morbidity and mortality $[1,12,13]$, there are still operational problems slowing down the scaling up of Insecticides Treated bed nets (ITN) usage such as seasonal variation of ITN use in the community, equity and access constraints, low rates of net retreatment with insecticides and reports of insecticide resistance in malaria mosquitoes. With such problems facing the existing control measures against vector- borne diseases, there is a need to look for alternative and supplementary means to support existing control measures. Alternative, cost- effective and environmentally friendly bio-products such as plant repellents can potentially be improved to supplement existing vector- control measures [11]. Although there are many plant species used traditionally for protection against blood- feeding insects, there are few studies to illustrate their protective efficacy and or contribution to disease control. Following a survey conducted, OS and OK were the most common plants used as insects repellent by local communities at lower Moshi, north-eastern Tanzania [6]. This study evaluates deterrence, exophily and feeding inhibition effects of Ocimum suave (OS), Ocimum kilimandscharicum (OK), Azadirachta indica (AI) Eucalyptus globules (EG) and Lantana camara (LC) on three mosquito species, Anopheles arabien- sis (Patton), An. gambiae ss (Giles) and Cx. quinquefasciatus (Say) in the field and experimental huts.

\section{Methods \\ Study area}

The surveys were taken from January to March 2006, at Lower Moshi villages ( $37^{\circ} 20^{\prime} \mathrm{E}, 3^{\circ} 21^{\prime} \mathrm{S}$; $750 \mathrm{M}$ above sea level), located $19 \mathrm{~km}$ South of Moshi town, on the foot slopes of Mount Kilimanjaro. The area is fully described elsewhere [6]. The study was conducted at Mabogini, Rau Kati, Chekereni and Mtakuja villages located at Mabogini ward with an estimated population of 20,614, 4871 households and average of 4.2 people per house [14].

\section{The protective efficacy of plant materials in experimental huts and village houses}

The plant materials of OS, OK, AI, EG and LC, were the first five common plants used as repellents mentioned by the community members in previous study in this area [6]. The method used for insect protection is mainly burning of dry plant material. In this test, one kilogram of each plant material was burnt between 7 and $10 \mathrm{pm}$ in selected houses in the community and experimental huts as commonly used in the community.

In the experimental hut trials, two huts were selected, the test hut and control hut. The experiment had a binary setting. One hundred (100) female mosquitoes of 3 to 6 days old of the same species were released in each hut with a person sleeping under an untreated bed net. The plant materials, particularly the leaves [6] were picked up within the community areas then dried in the sun for a day before use in this experiment.

Plant materials were burnt only in the test hut. The next day mosquitoes were collected in Window traps and verandahs. Physiological conditions (unfed, blood fed and gravid) of mosquitoes collected were observed, then provided with $10 \%$ sugar solution for 24 hrs to score mortality.

In the village trial, eight houses were selected and grouped into four pairs each with two houses, i.e. the control and experimental houses. Volunteers slept under an untreated net in each of the trial houses, to protect them from being exposed to wild mosquitoes that might be infected. Effects of plant repellents on mosquitoes were observed for four consecutive days.

Field trial of extracts of Ocimum plants (community study) Four houses and four pairs of volunteers performing manlanding catch (MLC) at each house were involved to evaluate the protective effect of essential oil extracts from OS and OK. The volunteers were provided with anti-malarial prophylaxis during the study period. The first group was 
treated with OK (a solution with $20 \%$ OK essential oil); second group treated with DEET at similar concentration $(20 \%)$, third group with OS (a solution with $20 \%$ OS essential oil) and the fourth, a control group treated with a mixture of glycerine and acetone. The $20 \%$ solution of OK, DEET and OS were prepared by dissolving crude essential oil into glycerine and acetone to a final concentration of $20 \%$. The proportion of major active ingredients in that sample (OK, OS and DEET) was used to derive the concentration of $20 \%$ which was used in this evaluation. The amount of oil used by volunteer was determined by measuring the weight of oil with bottle before and after application on feet. The repellent and control were applied on feet below the knee. Volunteers seating on chair 5 meters apart outside the house collected mosquitoes landing on their lower legs and on their feet using an aspirator [15]. Collected mosquitoes were grouped in hourly intervals and identified using a morphological key $[16,17]$. Experiments were 4 by 4 Latin square arrangement, for four days per week for sixty-four weeks. The exercises started at 18:00 $\mathrm{h}$ and ended at 22:00 h. Both insect collectors and treatments were interchanged to prevent bias. Experiments were done for 4 days in a week and each treatment was rotated with same pair of volunteers. Treatments were interchanged between the groups alternatively in every week of trial. DEET, a known standard repellent was used for comparison in this evaluation.

\section{Ethical clearance}

Ethical clearance was reviewed and granted by Ethics committee of Tumaini University at Moshi in Tanzania. Oral and written consents were given to volunteers before starting the study and participation was voluntary.

\section{Statistical analysis}

Total hourly and nightly collections in human landing catch were quantified for An. arabiensis and Cx. quinquefasciatus, and biting inhibition was calculated as percentage differences between treated and untreated exposure. The mean mosquito numbers were computed on weekly basis so as to have reasonable number of mosquitoes. The protection efficiency was determined for each week and average for 64 weeks calculated as percentage average protective efficiency following the $4 \times 4$ Latin square designs. The percentage protection was estimated by Abbot Formula as $P E=\left(N_{C}-N_{T}\right) / N_{C} \times 100 \%$, where $N_{C}$ and $\mathrm{N}_{\mathrm{T}}$ are the mean number of mosquito landed on control and on treatment, respectively $[18,19]$. Data were subjected to analysis of variance (ANOVA) on repeated measures using a Latin square design. Mean percentage protection between treatments and protection against DEET were compared by sample $\mathrm{T}$ - tests, and the significance level was determined at $\mathrm{P}<0.05$.

In the experimental trial, data on mosquitoes found inside, on window traps or verandas, unfed and blood fed for both test and control huts were entered in MS Excel spreadsheet and used to calculate deterrence and feeding inhibition. The results were considered to be significant with an alpha value less than $5 \%$.

\section{Results \\ The efficacy of Ocimum plant extracts in the community field study}

In the field study, 1708 Anopheles gambiae s.l and 1093 Culex quinquefasciatus were collected in 64 weeks of Man Landing Catch. Anopheles arabiensis is the commonest Anopheline species accounting for $61.2 \%$ of all collected mosquitoes. All An. gambiae s.l. were presumed to be An. arabiensis following previous identification records in the area [20].

All tested compounds showed significant protection efficiency (PE) to human volunteers against all mosquito species. The PE for An. arabiensis was $93.44 \%$ for DEET, $91.98 \%$ for OS and $89.75 \%$ for OK (Table 1 ). The mean number of An. arabiensis caught per night for each treatment and control are shown in Table 1. The lowest and highest numbers of mosquitoes landing per night by type of treatment are indicated as $95 \% \mathrm{CI}$.

In Cx. quinquefasciatus, the PE was $91.30 \%, 88.65 \%$ and $90.50 \%$ for DEET, OS and OK respectively. Although the PE of all products was more than $88 \%$, the magnitude of protection by $\mathrm{OK}$ and DEET against $C x$ quinquefasciatus was comparable (Table 2). The mean number of An. arabiensis caught per night for each treatment and control are shown in Table 2. The lowest and highest numbers of mosquitoes landing per night by type of treatment are indicated as $95 \%$ CI.

Table I: Protective efficiency of standard repellent DEET, extracts of Ocimum suave and Ocimum kilimandscharicum to Anopheles arabiensis in the field evaluation estimated by human landing catch conducted for a total of 64 weeks.

\begin{tabular}{ccccc}
\hline Treatment & \% Protection & Anopheles collected & Collections/night (Mean \pm SE) & $95 \%$ Cl \\
\hline OS & 91.98 & 137 & $2.28 \pm 0.499$ & $1.29-3.28$ \\
OK & 89.75 & 175 & $2.92 \pm 0.726$ & $1.46-4.38$ \\
DEET & 93.44 & 112 & $1.87 \pm 0.474$ & $0.92-2.82$ \\
Control & 24.82 & 1284 & $21.4 \pm 2.809$ & $15.78-27.02$ \\
\hline
\end{tabular}


Table 2: Protective efficiency of standard repellent DEET, extracts of Ocimum suave and Ocimum kilimandscharicum to Culex quinquefasciatus in the field evaluation estimated by human landing catch conducted for a total of 64 weeks.

\begin{tabular}{ccccc}
\hline Treatment & \% Protection & Cx. quinquefasciatus collected & Collections/night (Mean \pm SE) & $95 \%$ Cl \\
\hline OS & 88.65 & 124 & $2.067 \pm 0.695$ & $0.68-3.46$ \\
OK & 90.5 & 103 & $1.72 \pm 0.412$ & $0.89-2.54$ \\
DEET & 91.3 & 95 & $1.58 \pm 0.526$ & $0.53-2.63$ \\
CONTROL & 29.46 & 771 & $12.85 \pm 2.23$ & $8.37-17.32$ \\
\hline
\end{tabular}

The efficacy of Ocimum and other plants in experimental huts

The impact of smoke from burned repellent plant materials in experimental huts was observed in 24 hours after burning. An increase in exophily behaviour (i.e. reduced indoor resting mosquitoes) and blood-feeding inhibition was observed. In experimental huts, high deterrence and feeding inhibition rates of $O$. suave, O. kilimandscharicum, Azadirachta indica, Eucalyptus globules and Lantana camara on An. arabiensis and Cx. quinquefaciatus were observed by collection of large numbers of these mosquitoes in window and verandah traps. Deterrence ranged from $79.4 \%$ to $88.9 \%$ and $71.2 \%$ to $86.9 \%$ while feeding inhibition ranged from $60 \%$ to $98.4 \%$ and $18.5 \%$ to $85.4 \%$ in $A n$. arabiensis and Cx.quinquefaciatus respectively (Table 3 ). The OK induce high deterrence in An. arabiensis while AI in Cx. quinquefasciatus and feeding inhibition (>90\%) in both species of mosquito tested. Performance of OS in terms of deterrence and feeding inhibition of An. arabiensis and $C x$. quinquefaciatus (range from $80 \%$ to $98 \%$ ) was much higher than those of EG and LC (range from $18.5 \%$ to $88.1 \%$ ), in particular LC induced the lowest effect in reducing feeding in Culex (Table 3). In general, the protec-

Table 3: Deterrence and feeding inhibition rates of Ocimum suave, Ocimum kilimandscharicum, Azadirachta indica, Eucalyptus globules and Lantana camara to An. arabiensis and Cx. quinquefaciatus in experimental huts.

\begin{tabular}{|c|c|c|c|c|c|c|c|c|c|c|c|c|}
\hline \multirow[t]{2}{*}{ Species } & \multirow[t]{2}{*}{ Observed condition } & \multicolumn{2}{|c|}{ os } & \multicolumn{2}{|c|}{ OK } & \multicolumn{2}{|c|}{ Al } & \multicolumn{2}{|c|}{ EG } & \multicolumn{2}{|c|}{ LC } & \multirow{2}{*}{$\begin{array}{l}\text { Deterrence } \\
\text { comparison }\end{array}$} \\
\hline & & Hut A & Hut B & Hut A & Hut B & Hut A & Hut B & Hut A & Hut B & Hut $A$ & Hut B & \\
\hline \multirow[t]{6}{*}{ An. arabiensis } & Resting Indoors & 0 & 891 & 04 & 684 & 0 & 784 & 0 & 818 & 39 & 851 & $P=0.07$ \\
\hline & Outdoors (WT + VT) & 883 & 101 & 872 & 96 & 902 & 198 & 774 & 92 & 710 & 146 & \\
\hline & $\%$ Deterrence & \multicolumn{2}{|c|}{88.6} & \multicolumn{2}{|c|}{88.9} & \multicolumn{2}{|c|}{$\mathbf{8 8 . 0}$} & \multicolumn{2}{|c|}{88.1} & \multicolumn{2}{|c|}{79.4} & \\
\hline & Unfed & 869 & $|7|$ & 840 & 110 & 879 & 142 & 680 & 104 & 600 & 107 & \\
\hline & Fed & 14 & 821 & 32 & 670 & 23 & 850 & 94 & 806 & 149 & 890 & \\
\hline & $\begin{array}{l}\% \text { Feeding } \\
\text { inhibition }\end{array}$ & 98.4 & 17.2 & 96.3 & 14.1 & 87.9 & 14.2 & 68 & 10.4 & 60 & 10.7 & \\
\hline \multirow[t]{6}{*}{ Cx. Quinq. } & Resting Indoors & 11 & 754 & 0 & 280 & 15 & 843 & 0 & 879 & 94 & 790 & $P=0.10$ \\
\hline & Outdoors (WT + VT) & 901 & 179 & 620 & 98 & 922 & 120 & 896 & 102 & 698 & 201 & \\
\hline & $\%$ Deterrence & \multicolumn{2}{|c|}{80.1} & \multicolumn{2}{|c|}{84.2} & \multicolumn{2}{|c|}{86.9} & \multicolumn{2}{|c|}{86.1} & \multicolumn{2}{|c|}{71.2} & \\
\hline & Unfed & 854 & 189 & 570 & 40 & 833 & 180 & 804 & 91 & 185 & 120 & \\
\hline & Fed & 47 & 744 & 50 & 215 & 104 & 783 & 92 & 890 & 607 & 871 & \\
\hline & $\begin{array}{l}\% \text { Feeding } \\
\text { inhibition }\end{array}$ & 85.4 & 18.9 & 91.9 & 15.7 & 83.3 & 18 & 80.4 & 9.1 & 18.5 & 12 & \\
\hline
\end{tabular}

Hut $A=$ Experimental hut with slowly burning plant materials and a person.

Hut $\mathrm{B}=$ Control Hut with a person alone.

WT $=$ Window trap

$\mathrm{VT}=$ Verandah Trap 
tive effects of the four plant repellents were much higher on An. arabiensis than $C x$. quinquefasciatus mosquitoes.

\section{The efficacy of Ocimum and other plants in selected community houses}

In the selected community houses, feeding inhibition ranged from $61 \%$ to $100 \%$ for An. arabiensis and from $50 \%$ to $100 \%$ for Cx. quinquefasciatus (Table 4). Likewise, deterrence ranged from $73.1 \%$ to $81.9 \%$ for An. arabiensis and from $56.5 \%$ to $67.8 \%$ for Culex. In particular, the EG induce high deterrence (89.1\%) while OS and OK have shown higher feeding inhibition $(100 \%)$ in both species of mosquito tested. Although the performance of other plants used in terms of (deterrence and) feeding inhibition of An. arabiensis and $C x$. quinquefasciatus (range from $50 \%$ to $100 \%$ ) was higher on treated houses, the difference was comparable to the effect recorded from control houses (range from $55 \%$ to $86 \%$ ) as shown in Table 4 . In general, the protective effect of plant repellents was much higher on Anopheles than Culex mosquitoes.

However, the deterrence effect of burning repellents in village houses have shown variations between treatment day and days before next treatment in reducing indoor resting mosquito (Figure 1). In general, day 0 of treatment recorded significantly low numbers of mosquitoes resting indoors than subsequent days of observation after treat- ment. The number of mosquitoes caught increased gradually on subsequent days after treatment, suggesting a lack of residual effect of smoke from repellent plant materials.

\section{Discussion}

The proper use of plant-based repellents against mosquitoes should have a role in reducing insect- borne diseases such as malaria, dengue and filariasis [9]. Most people at risk of malaria infection are in sub- Saharan Africa, the low-income group, disadvantaged people in the community and those living at marginal areas are badly affected by a malaria burden. In communities with low purchasing power, use of plant- based insect repellent is probably the best alternative available [21,22].

\section{Experimental huts and village house}

In both experimental huts and the trial in local village houses, a drastic reduction of indoor resting mosquitoes was observed when plant materials were burnt. The control huts and houses retained high and comparable numbers of indoor resting mosquitoes and blood feeding rates. These showed that the proper (continuous) use of the plant repellents in this area can effectively reduce mosquito population indoor as observed previously in West Africa [5]. Since plant repellents are used in most of modern houses constructed with concrete blocks with wire gauze on the windows this is an indication that, such

Table 4: Deterrence and feeding inhibition rates of Ocimum suave, Azadirachta indica, Eucalyptus globules and Lantana camara to An. arabiensis and $C x$. quinquefaciatus in village houses.

\begin{tabular}{|c|c|c|c|c|c|c|c|c|c|c|c|c|}
\hline \multirow[t]{2}{*}{ Species } & \multirow[t]{2}{*}{ Character observed } & \multicolumn{2}{|c|}{ OS } & \multicolumn{2}{|c|}{ OK } & \multicolumn{2}{|c|}{ Al } & \multicolumn{2}{|c|}{ EG } & \multicolumn{2}{|c|}{ LC } & \multirow{2}{*}{$\begin{array}{l}\text { Deterrence } \\
\text { comparisons }\end{array}$} \\
\hline & & $\mathrm{HSAl}$ & HS B & $\mathrm{HS}$ A2 & HS B & HS A3 & HS B & HS A4 & HS B & HS A5 & HS B & \\
\hline \multirow[t]{6}{*}{ An. arabiensis } & Resting indoor & 3 & 63 & 6 & 71 & 2 & 112 & 4 & 85 & 18 & 78 & $P=0.09$ \\
\hline & Outdoors (WT + VT) & 94 & 31 & 86 & 22 & 49 & 18 & 59 & 13 & 64 & 21 & \\
\hline & \% Deterrence & \multicolumn{2}{|c|}{75.2} & \multicolumn{2}{|c|}{79.6} & \multicolumn{2}{|c|}{73.1} & \multicolumn{2}{|c|}{81.9} & \multicolumn{2}{|c|}{75.3} & \\
\hline & Unfed & 3 & 34 & 2 & 35 & 5 & 68 & 3 & 48 & 11 & 43 & \\
\hline & Fed & 0 & 29 & 0 & 23 & 1 & 44 & 1 & 37 & 7 & 35 & \\
\hline & $\%$ Feeding inhibition & 100 & 53.9 & 100 & 60.3 & 83.3 & 60.7 & 75 & 56.5 & 61.1 & 55.1 & \\
\hline \multirow{6}{*}{ Cx. quinq } & Resting indoor & 2 & 21 & 3 & 33 & 10 & 21 & 2 & 11 & 2 & 7 & $P=0.12$ \\
\hline & Outdoors (WT + VT) & 26 & 17 & 31 & 23 & 19 & 11 & 15 & 9 & 19 & 9 & \\
\hline & \% Deterrence & \multicolumn{2}{|c|}{56.5} & \multicolumn{2}{|c|}{57.4} & \multicolumn{2}{|c|}{63.3} & \multicolumn{2}{|c|}{62.5} & \multicolumn{2}{|c|}{67.8} & \\
\hline & Unfed & 2 & 5 & 2 & 7 & 8 & 6 & 4 & 3 & 2 & 2 & \\
\hline & Fed & 0 & 16 & 0 & 13 & 2 & 14 & 4 & 8 & 0 & 6 & \\
\hline & $\%$ Feeding inhibition & 100 & 23.8 & 100 & 35.0 & 80 & 30.0 & 50.0 & 27.3 & 100 & 25.0 & \\
\hline
\end{tabular}

HS Al to HS A4 = Houses in the village with two occupants in which plant materials were bunt.

$\mathrm{HS} B \mathrm{~B}$ to HS B4 = Houses in the village with two occupants which were used as Control houses. 


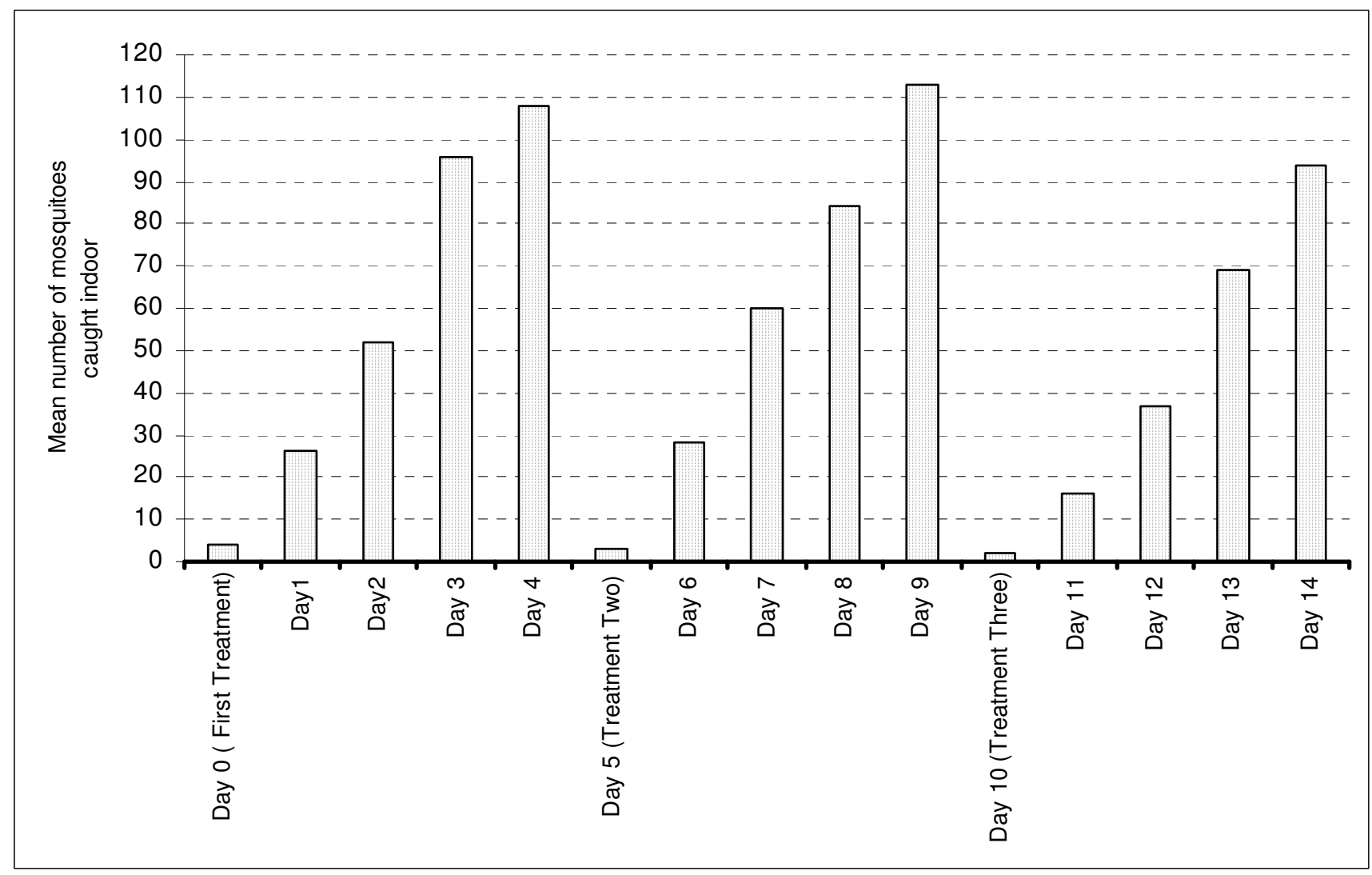

Figure I

The response of mosquitoes to repellent plant (Ocimum suave) burnt in village house in an interval of four days with three rounds of treatment.

improvements alone are not enough for protection against biting insects. This observation suggests that the concept of an integrated approach to vector management should be the norm, and therefore making it easier to introduce other control measures [22,23].

Increased knowledge and use of plant based repellent against mosquito bites in the community suggests that local people also see the advantages of plant-derived products over imported synthetic repellents or chemical pesticides [22]. Synthetic chemicals such as organochlorides do not readily degrade in nature and have been identified as ubiquitous pollutants in aquatic ecosystems $[24,25]$. Concern about the deleterious effects associated with synthetic acaricides and insecticides has revived interest in plants as alternative pesticides for medical, veterinary and crop protection [8]. Even non-human vertebrates use aromatic-arthropod-repellent plants to avoid ectoparasites by rubbing them in the skin [26,27]. Generally, the natural plant products, with a few exceptions, tend to be rather slow-acting, of modest toxicity and rapidly degrade in the environment [28]. Plant- based repel- lents have multi- active sites in their chemical structures making it difficult for insects to develop resistance. So far, resistance against plant repellents has not been reported [8] as has been the experience with synthetic pyrethroids on bednets [29]. Moreover, plant- based repellents may be more economical than commercially available synthetic chemicals for use in low-income communities. Such cheap, readily available plant repellents can easily be promoted for a wider community use especially in poor rural communities in Tanzania.

\section{Community trials of plant extracts against biting mosquitoes}

In this study, the protective efficacy (PE) of the OS and OK natural products against $A n$. arabiensis and $C x$. quinquefaciatus was high (range: $84 \%-89 \%$ ) and comparable to a standard repellent, DEET (range: $88 \%$ to $91 \%$ ). This agrees with previous studies reporting significantly higher repellence and feeding inhibition against An. gambiae and $C x$. quinquefasciatus, and feeding inhibition by $\mathrm{OK}$ was higher than OS $[9,30,31]$. Furthermore, Ocimum species has been reported to reduce the biting activity of the An. 
gambiae by more than $40 \%$ in semi-field experiments [32]. The variation in repellence effects between OS and OK ought to be associated with differences in concentrations of other compounds, such as linalool and camphor $[30,33]$. Linalool is found in high concentrations in OS whereas camphor is found in high concentrations in OK [7]. This variation has been reported to cause different responses in the rate of mortalities in Coleoptera of agricultural importance [34].

Although these natural products have demonstrated a significant protection against malaria and nuisance mosquitoes, their major handicap has been relatively high volatility of many of its monoterpenoid ingredients, leading to rapid loss of protection. In comparison with DEET which has long duration of protection [12] duration of the protective effect by OS and OK extracts was reduced. On the other hand, volatility of ingredients of essential oils contributes to spatial repellence affecting the insects flying in the vicinity [22]. Indeed the formulation to extend the duration of release of volatiles of extracts from repellent plants will improve the protective effects against insects. These data show that natural products emit sufficient quantities of volatiles for protection against mosquitoes under field conditions, as has been reported elsewhere $[33,35]$. These findings suggest that such natural products can potentially be used as an alternative and cheaper means of malaria control in poor communities.

Among the natural products tested, biting inhibition by OS was generally higher than that of OK. Evidence of higher biting inhibition and protection observed on both OS and OK justify further investigation. This should focus on the improvement of formulations to increase the potency and identify deployment strategies adaptable for local communities.

\section{Conclusion}

This study of two most common plant repellents in north eastern Tanzania, the Ocimum suave and Ocimum kilimandscharicum, revealed significant protective effect by reducing both the indoor resting mosquitoes and inhibiting mosquito blood- feeding. There is a need to investigate the most efficient deployment methods to the community, product toxicological and safety assessment of extracts or plant fumes, improve formulations and research on the impact of such intervention on disease outcome. The Ocimum repellent plants are abundant and locally available, therefore readily acceptable in the community. Moreover, plant- based repellents may be more economical than the commercially available synthetic chemicals for use in low-income communities. Such cheap, readily available plant repellents can easily be promoted for a wider use, especially in poor, rural communities in Tanzania.

\section{Competing interests}

The authors declare that they have no competing interests.

\section{Authors' contributions}

EJK, FWM and EAT designed the study, participated in analysis and interpretation of data and drafted the manuscript. FT, AL and AMM carried out data analysis and interpretation, and were involved in the drafting of the manuscript. EJK, MJM, CM, EL, and MM reared mosquitoes and performed experiments. All authors read and approved the final copy of this manuscript.

\section{Acknowledgements}

The study was made possible through a grant awarded to EJK by Belgium Technical Co-operation as part of his MSc scholarship. This work would not have been a success without participation of the communities of Mabogini, Rau Kati, Mtakuja and Chekereni villages, their cooperation is highly appreciated. Vector control project staffs at KCMC are acknowledged for their kind support. Prof. Ndiega, Dr Lwande and Mr. Maxwell Mulumbasi of ICIPE, Kenya are highly acknowledged for literature provision and extraction of essential oils from plant materials.

\section{References}

I. Berger A: Using natural pesticides: current and future perspectives. In Swedish University of Agricultural Sciences Alnarp, Sweden; 1994.

2. Berger A, Curtis CF: Natural plant products as pesticides. In Swedish University of Agricultural Sciences Alnarp, Sweden; 1995:45.

3. Curtis CF, Lines JD, Baolin L, Renz A: Natural and synthetic repellents. In Control of disease vectors in the Community Edited by: Curtis CF. Wolf publisher limited, London; 1991:75-92.

4. Palsson K, Jaenson TG: Comparison of plant products and pyrethroid-treated bed nets for protection against mosquitoes (Diptera: Culicidae) in Guinea Bissau, West Africa. J Med Entomol 1999, 36:|44-|48.

5. Palsson K, Jaenson TG: Plant products used as mosquito repellents in Guinea Bissau, West Africa. Acta Trop 1999, 72:39-52.

6. Kweka EJ, Mosha FW, Lowassa A, Mahande AM, Kitau J, Matowo J, Massenga P, Tenu F, Feston E, Lyatuu E, Mboya M, Mndeme R, Chuwa $G$, Temu EA: Ethnobotanical study of some of mosquito repellent plants in north-eastern Tanzania. Malar J 2008, 7: I 52.

7. Chogo JBA, Crank G: Chemical composition and biological activity of the Tanzania plant Ocimum suave. J Nat Prod I98I, 44:308-309.

8. Jembere B, Obeng-Ofori D, Hassanali A, Nyamasyo GHN: Products derived from the leaves of the Ocimum kilimandscharicum as post-harvest grain protectants against the infestation of three major stored product insect pests. Bull Entomol Res 1995 , 85:336I-3367.

9. Omolo MO, Okinyo D, Ndiege IO, Lwande W, Hassanali A: Repellency of essential oils of some Kenyan plants against Anopheles gambiae. Phytochemistry 2004, 65:2797-2802.

10. Omolo MO, Okinyo D, Ndiege IO, Lwande W, Hassanali A: Fumigant toxicity of the essential oils of some African plants and constituents of Conyza newii (Compositeae) against Anopheles gambiae senso stricto. Phytomed Res 2005, I 2:24|-246.

II. Weidhaas DE, Focks DA: Management of the arthropod borne diseases by Vector control. In Medical Entomology, A textbook on public health and veterinary problems caused by arthropods Edited by: Bruce F. Eldridge, John D. Edman. Kluwer Academic publishers; 2004:539-563.

12. Curtis CF, Lines JD, ljumba J, Callaghan A, Hill N, Karimzad MA: The relative efficacy of repellents against mosquito vectors of disease. Med Vet Entomol 1987, I:109-119.

13. Alonso PL, Lindsay SW, Armstrong Schellenberg JR, Keita K, Gomez P, Shenton FC, Hill AG, David PH, Fegan G, Cham K: A malaria control trial using insecticide-treated bed nets and targeted chemoprophylaxis in a rural area of The Gambia, West Africa. 
6. The impact of the interventions on mortality and morbidity from malaria. Trans R Soc Trop Med and Hyg 1993, 87:37-44.

\begin{tabular}{l} 
14. National census report 2002 [http://www.tanzania.go.tz/cen \\
\hline
\end{tabular} susdb/index.html]

15. World Health Organization: Manual on practical entomology in malaria. Part II. In Prepared by the WHO division of malaria and other parasitic disease World Health Organiz. Geneva; 1975.

16. Gillies MT, de Meillon B: The Anopheline of Africa south of the Sahara. South African Institute for Medical Research, Johannesburg 1968:343.

17. Gillies MT, Coetzee M: A Supplement to the Anopheline of Africa south of the Sahara. South African Institute for Medical Research, Johannesburg 1987:143.

18. Abbott WS: A method of computing the effectiveness of an insecticide. 1925. J Am Mosq Control Assoc 1987, 3:302-3.

19. Mehr ZA, Rutledge LC, Morales EL, Meixsall VE, Korte DW: Laboratory evaluation of controlled released insect repellent formulations. J Am Mosq Control Assoc 1985, I: 143-147.

20. ljumba JN: The impact of rice and sugarcane irrigation on malaria transmission in the lower Moshi area of northern Tanzania. In Zoological Institute of Copenhagen Denmark PhD thesis; 1997.

21. Gallup J, Sachs J: The economic burden of Malaria. Am J Trop Med and Hyg 200I, 64:85-96.

22. Hill N, Lenglet A, Arnéz M, Carneiro I: Plant based insect repellent and insecticide treated bed nets to protect against malaria in areas of early evening biting vectors: double blind randomised placebo controlled clinical trial in the Bolivian Amazon. BM/ 2007, 335: 1023.

23. Rozendaal JA: Vector Control: Methods for use by Individuals and Communities, Geneva. World Health Organiz 1997:4I2.

24. Mulla MS, Su T: Activity and biological effects of neem products against arthropods of medical and veterinary importance. J Am Mosq Control Assoc 1999, 15:133-152.

25. Aquino M, Fyfe M, MacDougall L, Remple V: Protective behaviour survey, West Nile virus, British Columbia. Emerg Infect Dis 2004, I0:1499-I50I.

26. Duke: Phytochemical and Ethnobotanical Databases. [http:// www.ars-grin.gov/duke/].

27. Wimberger PH: The use of green plant material in birds nests to avoid ectoparasites. Auk 1984, 101:615-18.

28. Koul O, Dhaliwal GS: Phytochemical Biopesticides. Harwood Academic Publishers, Amsterdam, The Nertherland; 200 I.

29. Chandre F, Darriet F, Darder M, Cuany A, Doannio JM, Pasteur N, Guillet $P$ : Pyrethroid resistance in Culex quinquefasciatus from west Africa. Med Vet Entomol 1998, I 2:359-366.

30. Hassanali A, Lwande W, Ole-sitayo N, Moreka L, Nokoe S, Chapya A: Weevil repellent constituents of Ocimum suave leaves and Eugenia caryophyllata cloves used as grain protectant in parts of Eastern Africa. Discovery and innovations 1990, 2:91-95.

31. Odalo JO, Omolo MO, Malebo H, Angira J, Njeru PM, Ndiege IO, Hassanali A: Repellency of essential oils of some plants from the Kenyan coast against Anopheles gambiae. Acta Trop 2005, 95:210-218.

32. Seyoum A, Killeen GF, Kabiru EW, Knols BG], Hassanali A: Field efficacy of thermally expelled or live potted repellent plants against African malaria vectors in western Kenya. Trop Med Int Health 2003, 8:1005-I0II.

33. Casida JH: Pesticide mode of action: evidence for and applications of a finite number of biochemical targets. In Pesticides and alternatives: innovative chemical and biological approaches to pest control Edited by: Casida JE. Amsterdam, Elsevier; 1990:I I-22.

34. Weaver DK, Dunkel FV, Ntezurubranza L, Jackson LL, Stock DT: The efficacy of Linalool, a major component of freshly-milled Ocimum canum (Sims) (Lamiaceae), for protection against post harvest damage by certain stored product Coleoptera. J stored prod Res 1991, 27:2 13-320.

35. Seyoum A, Palsson K, Kung'a S, Kabiru E, Lwande W, Killeen G, Hassanali $A$, Knols B: Traditional use of mosquito-repellent plants in western Kenya and their evaluation in semi-field experimental huts against Anopheles gambiae: ethnobotanical studies and application by thermal expulsion and direct burning. Trans R Soc Trop Med and Hyg 2002, 96:225-23I.
Publish with Bio Med Central and every scientist can read your work free of charge

"BioMed Central will be the most significant development for disseminating the results of biomedical research in our lifetime. "

Sir Paul Nurse, Cancer Research UK

Your research papers will be:

- available free of charge to the entire biomedical community

- peer reviewed and published immediately upon acceptance

- cited in PubMed and archived on PubMed Central

- yours - you keep the copyright

Submit your manuscript here:

http://www.biomedcentral.com/info/publishing_adv.asp
BiolMedcentral 